This item was submitted to Loughborough's Research Repository by the author.

Items in Figshare are protected by copyright, with all rights reserved, unless otherwise indicated.

\title{
Toby Miller on Cultural Studies
}

\section{PLEASE CITE THE PUBLISHED VERSION}

https://uk.sagepub.com/en-gb/eur/big-ideas-in-social-science/book245011\#description

\section{PUBLISHER}

(c) Sage

\section{VERSION}

VoR (Version of Record)

\section{PUBLISHER STATEMENT}

This work is made available according to the conditions of the Creative Commons Attribution-NonCommercialNoDerivatives 4.0 International (CC BY-NC-ND 4.0) licence. Full details of this licence are available at: https://creativecommons.org/licenses/by-nc-nd/4.0/

\section{LICENCE}

CC BY-NC-ND 4.0

\section{REPOSITORY RECORD}

Miller, Toby. 2019. "Toby Miller on Cultural Studies”. figshare. https://hdl.handle.net/2134/23249. 


\section{2 \\ TOBY MILLER ON CULTURAL STUDDES}

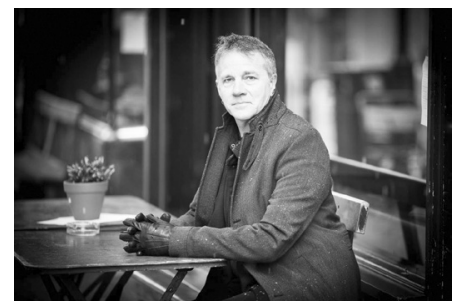

Toby Miller is Emeritus Distinguished Professor at the University of California, Riverside, the Sir Walter Murdoch Professor of Cultural Policy Studies at Murdoch University, and Professor of Journalism, Media and Cultural Studies at Cardiff University/Prifysgol Caerdydd. He can be contacted at tobym69@icloud.com and his adventures scrutinized at www.tobymiller.org.

David Literature, physics, history, now these are proper areas of academic Edmonds: discipline. But Cultural Studies? Even compared to the other Social Sciences, Cultural Studies has attracted - from usually ignorant sources - particular derision. Toby Miller is a leading academic in Cultural Studies whose writings cover an astounding range of topics from TV and Hollywood to sport and the media.

Nigel The topic we're focusing on is Cultural Studies. Could you begin

Warburton: by saying something about what you do, and why that's Cultural Studies?

Toby Sure. I think the answer to the question 'What is Cultural Miller: Studies?' is ongoing and depends on the time and place that it's answered, although the same thing could be said about lots of disciplines as they merge through time, warp and woof, and interact with others. In my case I try to look at two particular factors in the everyday life of culture. The first is subjectivity, by which I mean not just 'this is simply my opinion', but rather how subjects are made, how persons are constructed, how 
positions are generated for them and how they occupy those positions - whether that's something the census says about you, or your mother says about you, or your religious affiliation says about you. Secondly, power: how those subjects are constructed in terms of different power dynamics, hierarchies, and opportunities for difference and contestation.

NW: $\quad$ This idea of the relationship between the self and society sounds like sociology to me.

TM: $\quad$ Well, it's true that I'm a lapsed sociologist! But because my career's been split between Australia, the US, the UK and Latin America, I'm prone to different kinds of sociology. The one that most appeals to me is probably the more qualtoid, politically inflected, culturalist form you get in Latin America, and less the 'rats and stats' quantoid form that predominates in the United States.

NW: $\quad$ Could you give an example of something that is Cultural Studies? What makes it 'cultural'?

TM: $\quad$ By 'culture' most of us in the field would mean two things. First of all, what's often thought of as an aesthetic inheritance or an aesthetic heritage, namely the world of arts, the world of meaning, the world of textuality, the world of content. The way in which artists, authors, writers, radio producers, generate things of beauty, things of truth, if you like - what we understand by 'the Arts' or 'the Humanities'.

Secondly there is an understanding of culture which is more ethnographic, perhaps more anthropological. This is about customary ways of life: the understanding that society is authored not only through formal rules and regulations but informal ones - the way in which we organize our daily routines, the way in which you and I are taking turns - politely, so far - with each other's sentences. And in cultural studies those things merge. In order to understand how art works, you need to understand everyday life, and in order to understand everyday life, you have to understand how art works. And that's especially true in many of the de-industrialising, post-industrialised societies like the UK and the US. Increasingly in these places, services, culture, ideas, meanings, insurance, law, and the media are being sold, not farming, manufacturing, or mining. 
To give an example, do you like Hollywood, Nigel? What do you think about the Hollywood industry as a consumer, as a viewer?

NW: $\quad$ I tend to go a bit more for the independent films... there are some great Hollywood movies, for sure.

TM: $\quad$ This is the edgy, arty side of Nigel Warburton exposed to his multinational public. Well, in the books Global Hollywood and Global Hollywood 2 that I wrote with a number of collaborators with Indian, Chinese, Spanish and US backgrounds, we tried to understand the success of Hollywood as a film industry around the world in many different contexts, but always trying to bear in mind three factors.

First, the underpinning political economy - in other words who benefits from all of this? How does the money move? Is the success of Hollywood not just about the supposed quality of what it produces, but its capacity to get hold of things like free money? In other words, not loans and not equity, but lunatic governments throwing money at it because they think Hollywood will produce glamour, tourism, or whatever.The UK is lunatic about that, Australia is, Hungary is - you name it.

A second aspect of all this, of course, is the meaning of these things. How is the success of Hollywood achieved through sights, sounds, narratives, and dramatic arcs? What are the special effects that generate the meanings that stand for Hollywood when you and I use the term?

And, thirdly, how are these things actually interpreted: what do we know about how audiences make meanings themselves as recipients of Hollywood?

So in other words, the way I do Cultural Studies is to examine ownership, control, regulation and so on; the meaning that's generated; and the experience of that meaning as it is in turn regenerated by audiences or spectators.

NW: It strikes me that there are two distinct things going on: you're collecting empirical data about Hollywood, and presumably that's reasonably objective, but you are also spinning a story about Hollywood and that surely has a subjective element. How do you know that the story that you're spinning about Hollywood is a plausible story? 
TM: $\quad$ That's a really good question, because Hollywood in particular is one of these places where vast amounts of data are available. And one can deem them to be real and credible. But frankly they encourage words that one can't say on Social Science Bites but are running through our minds even as we speak. So when you go to sources like the major trade magazines, or the studios themselves, it's likely that you'll be told stories about, say, the success of Skyfall, a big James Bond movie - it cost this amount of money, it's taken in this amount of money, it will go through the following 'windows of release' that will generate the following revenue - and these stories are frequently fabricated. The only way you'll ever find out the real data is when there's a big law case and the books are opened in court. But, yes, we try to use lots of so-called 'hard' data that are about where the money goes. Some of that's reliable and some of isn't.

However, to get to your question about how I spin the story, how I know that my story is legitimate, that's a very reasonable point. I'm a polemical writer, and I want to tell stories that appeal, firstly, to other scholars and so will meet the standards of rigour that are expected within the various disciplines that are germane to the topic I'm interested in; secondly, to stakeholders who will actually pay some heed to what I write; and thirdly, to the general public. Some people, when they read my academic prose, say "extraordinary empirical data - it's a pity this person is so biased.'

NW: $\quad$ But you don't think it's biased?

TM:

No, I don't. My personal, political, intellectual commitments are very important to the work I do, but they don't structure or inform it in a totalizing way. My overall commitment is to try to find out the nature of things and how they operate. That often means unveiling things that are very uncomfortable in terms of my political commitments. More generally, it means disclosing things that are uncomfortable for other people's political commitments. So, for example, most people think Hollywood is a truly laissez-faire private enterprise industry, an example of the grandeur of American capitalism, the capacity to simply let entrepreneurs have their head without state intervention. That's simply not true. I've disproved 
it, as have many other people, hundreds of times. But there are plenty of people who say 'You're a socialist, that's what you're looking for, you don't understand that that's really irrelevant'. But my politics do not override the empirical material that I uncover.

NW:

How can you be sure of that?

TM:

Well, I get my work read by others who do not share my commitments. And I write so often and so much, but generally with time to spare, that I can go back and cast a critical gaze over what l've done. In terms of the Hollywood material, one of the interesting things to me is that I know producers, studio executives and Hollywood attorneys, who read the book and introduce me to others and say 'This is Toby Miller, he's a professor at the University of California (which I was), he's a socialist, but he actually understands how we go about what we do.'

That would be one case where l'm making a point about the hidden subsidies that characterize much of US capitalism: it's informed by what I suspect I'll find, as a consequence both of my social science background and my political commitments. And then when I find it, I have a diagnosis that I think is perfectly legitimate. But you don't have to accept the diagnosis in order to recognize that I am correct in the empirical material that I present.

NW: $\quad$ Have you ever had the experience of taking your interpretation of events, or of an institution, back to the people who know it intimately and have them saying 'That's not us, it's nothing like us'?

TM: $\quad$ Yes, I have. And frequently that's been an interesting lesson in and of itself. Whilst it's the case that a number of people working in Hollywood have found my analysis of their success and how they go about it very compelling, others have completely refused to engage or have denounced it, because, in my view, the reality of the degree of state participation in the success of this apparently laissez-faire industry is tough for them to hear.That doesn't mean their story, their version of these things, is worthless. I want to make sure that the voices that disagree with me are given plenty of space in what I write. 
NW: $\quad$ When I interviewed the psychologist Jonathan Haidt for Social Science Bites, he told me how he'd moved from having strong Democratic convictions more towards Republicanism, as a result of his research. Is there anything similar you could envisage happening to you?

TM: $\quad$ My view is constantly changed by what I unearth and what I encounter and what people tell me. An instance of that would be my work for the book, Sportsex, about sport and sexuality. As part of my commitment to try to reach out to scholars, to stakeholders, to the general public, I wrote newspaper op-eds, and a couple of pieces in fashion outlets and gay websites, at their request. One of those pieces was then re-appropriated by another website and illustrated with hardcore porn, without my being told, without the earlier gay website being told, and with no name responsible on the website other than, apparently, mine.

What was I to do with this? What was it telling me? There are ethical and legal issues, but put those to one side. I learnt from the episode that my writing in Sportsex, which was an attempt to talk about the beauty of the male body as a grand, new, vibrant commodity in the media, sport, and the public life of bodies, was amenable to this profoundly erotic/pornographic interpretation. So here I was finding my words illustrated, without my say-so, by images that many people would find deeply offensive - and yet there are some readers out there for whom this connection was quite significant. So it was a very interesting lesson in what can happen when you put your foot into the water, in a certain domain, when suddenly information can come back to you that's at variance with what you were anticipating.

NW: $\quad$ I was intrigued when you said earlier that your role is to disclose 'the nature of things'. Because the caricature of people in Cultural Studies is that they don't think there is a nature of things, everything is constructed, there's always another perspective. But you seem to be embracing an Enlightenment view of our relationship to the external world.

TM: $\quad$ Caught out! I thought that one was going over the boundary, but I got caught in the deep. My answer to that would be to turn to Bruno Latour - one of the great French 
anthropologists/philosophers/sociologists of science. When Latour is asked about the nature of science, the nature of things, and the nature of meaning, he says you have to have all three in dynamic intercourse (as the actress said to the bishop).

So let me give you an example of what I mean, what Latour means, and how that informs my understanding. Yes, there are all kinds of different natures of things: things evolve and the struggles over what they are and how to deal with them evolve, and the struggle over how to represent them evolves, but all those three things need to be understood if you're going to get to the nature of things.

Latour has an example. Suppose you're a scientist and you are writing an article about a particular thing that exists in the natural world - let's say wind. On the one hand there is a thing called 'wind'; nobody in Cultural Studies is going to say that the flag is not blowing when the flag is blowing. But the decision to write about the flag, and the funding that comes to you to do so, will involve social forces, power relations, government decisions, financial investments, and so on. And the way in which you write about the wind will be informed by the rules of how to write a journal article: there will be an abstract, keywords, a method; there will be a literature search; and there will be a hypothesis. None of these things has anything to do with wind: it's to do with a set of forces and to do with texts. So to understand the nature of things, you need to have all those things in dynamic play.

NW: $\quad$ But when it comes to the interpretation of the significance of things there's much more scope for debate than there is about the hard empirical data.

TM: $\quad$ Yes, but deciding what to count and how to count it is incredibly important. Justin Lewis, a wonderful British scholar, wrote a great book on public opinion about a decade ago. Justin's point there is that basically what happens with a lot of numerical sociology and communication studies is that there's a problem that exists which you can describe with words. We're talking on the day of the US presidential election: who is going to win between President Obama and Governor Romney? That will be decided empirically by numbers, but it 
is being constructed as a problem verbally. Once you've got that verbal problem, what it is that you want to know about, you then seek to turn the different categories that you've described into numbers: $X$ number of people are doing this, $Y$ number of people are doing that. Once you've done that and you go through the various numerical manipulations required of, say, mathematical sociology, your next task is to turn them back into words, so that people can interpret them. So in fact the semiotics of data collection, administration, manipulation and so on, are riddled with questions of representation. Each time we decide to count something, the 'thing' is also a word, and hence subject to contestation via its definition, salience, and use. And each time we arrive at an understanding based on quantitative methods, we have to explain them in natural language - back to definition, interpretation, and contestation.

NW: $\quad$ Cultural Studies has a bad press in Britain and possibly elsewhere in the world. Why do you think that is?

TM: $\quad$ In Britain it's often regarded as a 'Mickey Mouse' subject - that's actually the language used.You find plenty of people invested in the elite universities such as Oxford and Cambridge decrying it. You get people within media institutions like the BBC or the Guardian decrying it. You get plenty of people who are worried about so-called 'standards of education' decrying it.

Cultural Studies is going through the same growing pains and denunciations that sociology did after the Second World War, that literature did in the late nineteenth century and that the natural sciences did in the early twentieth century. In other words, when you have massive, imperial and economic changes to the way in which a country functions, the knowledge which is generated in universities to deal with those transformations has trouble getting a place at the table amongst those who have been trained in other domains.

If you went back a century and a bit to look at the way that English literature was denounced as 'Mickey Mouse' - though unfortunately they didn't have Mickey in those days - by contrast with Ancient Greek and Latin, you'd find extraordinary similarities.

In the US, Cultural Studies is associated much more with literature. So the historic task of high culture, its Arnoldian/Reithian 
mission in British terms, was to elevate the citizenry. That is supposedly being thrown to the wolves by literature professors, who instead of understanding that vocation, are instead obsessed with dross. In the US, the criticism is that obsessions with political correctness and the popular are diminishing the capacity to undertake the historic mission of literature: offering a disinterested view of human interaction and the social world that is about mythic quintessences rather than conflicts, classes, or genders.

NW: It doesn't follow that because something is despised now, it has value that will emerge as history unfolds.

TM: $\quad$ You're absolutely right, and of course we're in an era when areas like academic publishing are changing very rapidly, the interrelationship of the media and universities is changing very rapidly, and the commodification of knowledge is changing very rapidly. And unless Cultural Studies manages, on the one hand, to satisfy some of those requirements and modify itself to the prevailing political economy, and on the other hand, to find methods, forms, and norms that are legible to more traditional university areas, as literature managed to do, it will have difficulties.

But if we go back to the 1950s, to C.P. Snow, the great physicist and novelist, and his 'Two Cultures' pamphlet, he lamented the fact that whether he was in Knightsbridge, London, or Cambridge, Massachusetts, when he spoke to literature professors, they didn't understand anything about laws of thermodynamics, whereas physics professors knew something about T.S. Elliot. Snow felt as though ne'er the twain shall meet. One of the benefits that Cultural Studies might offer if it manages to get friendly with the sciences and the social sciences is that it is actually very interested in how those things can intersect.

Let me give you an example that's organic and already happening. In electronic games, people in Cultural Studies can write code and understand how software and hardware interact, and people in computer science are interested in narrative and understand the imagery of different subjects. These people take the same drugs, wear the same clothes, sleep with the same people, and go to the same parties - and 
are no longer either physically or symbolically at opposite ends of campus. So if Cultural Studies can follow that kind of example, without losing its commitment to the questions that l've adumbrated, to do with subjectivity and power, it may have a future.

NW: Do you think the point of Cultural Studies is to understand things or to change them?

TM: $\quad$ Ah, this is your inner Marxist expressing itself! Those things are deeply connected. If you look at what people do who teach public policy, or tourism, or shipbuilding or architecture, or history, guess what - they are not just finding out truth for its own sake. They're actually deeply complicit with, and implicated in, the nature of the economy, how people are trained to participate in it, how state work is done, and the knowledge citizens have that helps make them the people they are. So there is no pure, unscarred form of knowledge that doesn't try to change things.

\section{FURTHER READING}

Richard Maxwell and Toby Miller, Greening the Media (Oxford University Press, 2012)

Toby Miller et al., Global Hollywood: No. 2 (University of California Press, 2011) 